\title{
Timing of larval release by the blue coral, Heliopora coerulea, in southern Taiwan
}

Received: 22 July 2004 / Accepted: 29 September 2004/Published online: 3 December 2004

(C) Springer-Verlag 2004

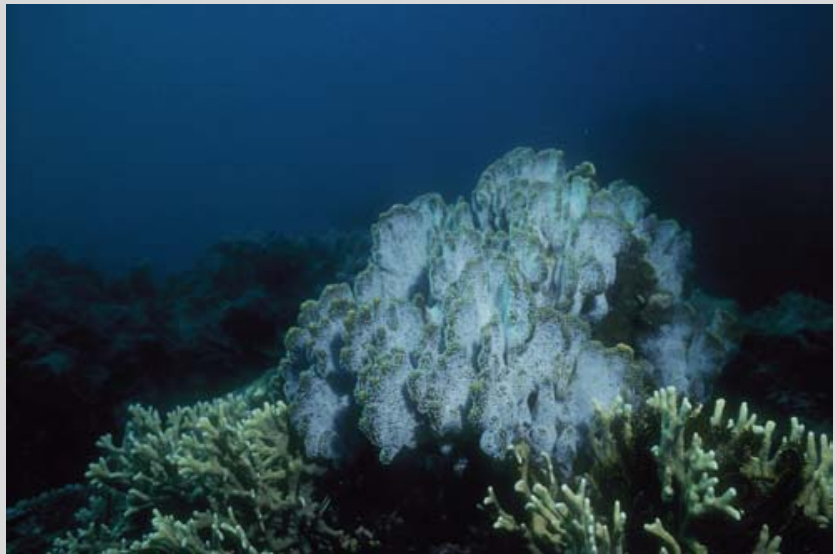

Fig. 1 A colony of the blue coral, Heliopora coerulea, with externally brooding larvae

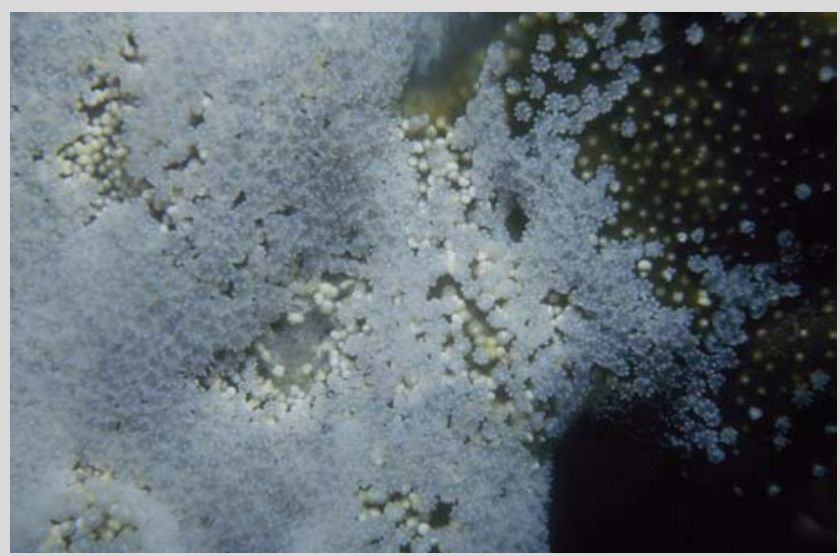

Fig. 2 Brooding larvae on the surface of the blue coral Heliopora coerulea
The blue coral Heliopora coerulea is a dioecious octocoral that has an annual gametogenetic cycle (Babcock 1990). The fertilized eggs develop into larvae in brooding cavities formed by the inflated tentacles on the surface of the female colony. This surface brooding behavior of $H$. coerulea, characterized by the white larvae and extended transparent polyps that densely cover the brown coenenchyme of the colonies, was observed at Wanlitung $\left(21^{\circ} 59.866^{\prime} \mathrm{N} ; 140^{\circ} 41.821^{\prime} \mathrm{E}\right)$ in southern Taiwan on 3 April 2002 (Figs. 1, 2).

Eight female colonies were collected, transported to the National Museum of Marine Biology and Aquarium, and maintained in outdoor flow-through aquaria on 5 April 2002. The brooded larvae were released during 14 to 22 April, with the peak on 17 April (lunar day 5). Most of the larvae were released in the daytime. Planulae are elongated, approximately $1250 \mu \mathrm{m}$, barrel-shaped, and white-colored due to the absence of zooxanthellae.

The larval release of $H$. coerulea in southern Taiwan occurred coincidently with the mass spawning of scleractinians which occurs in April and May (Dai et al. 1992). H. coerulea releases planulae in June or July in Ishigaki Island, southwest Japan (Harii and Kayanne 2003). However, the spawning of $H$. coerulea occurs in January in the Great Barrier Reef, Australia, which is 1 to 2 months later than that of mass spawning of corals (Babcock 1990).

Planula release by $H$. coerulea in southern Taiwan occurred during the new moon and first quarter moon phases with maximum planulation on lunar day 5 , corresponding to the incidence of neap tides. The benefit of planulation during neap tides may be that the larvae would remain in the same area for an extended period of time, thus, increasing the probability of recruitment near parent colonies or local retention

Acknowledgements This study was supported by a grant from the National Science Council, ROC (NSC 90-2621B-291-002).

\section{References}

Babcock R (1990) Reproduction and development of the blue coral Heliopora coerulea (Alcyonaria: Coenothecalia). Mar Biol 104:475-481

Dai CF, Soong K, Fan TY (1992) Sexual reproduction of corals in northern and southern Taiwan. In: Proceedings of the 7th international Coral Reef Symposium, Guam 1: 448-455

Harii S, Kayanne H (2003) Larval dispersal, recruitment, and adult distribution of the brooding stony octocoral Heliopora coerulea on Ishigaki Island, southwest Japan. Coral Reefs 22:188-196

P. J. Liu · T. Y. Fan ( ()

National Museum of Marine Biology and Aquarium, Pingtung 944, Taiwan, ROC

E-mail: tyfan@nmmba.gov.tw

Tel.: +886-8-8825001

Fax: $+886-8-8825085$

C. F. Dai

Institute of Oceanography, National Taiwan University, Taipei, 105, Taiwan, ROC

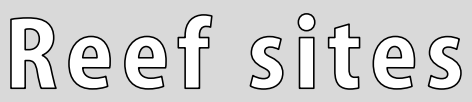

Coral Reefs (2005) 24: 30 DOI $10.1007 / \mathrm{s} 00338-004-0455-1$ 